\title{
Dates and Diabetes
}

\author{
Sandeep Chaudhary ${ }^{1}$ Aswin Pankaj² \\ ${ }^{1}$ Department of Endocrinology, NMC Hospital, Dubai, \\ United Arab Emirates \\ 2Department of Endocrinology, Jupiter Specialty Medical Centre, \\ Mankhool, Dubai, United Arab Emirates
}

\begin{abstract}
Address for correspondence Sandeep Chaudhary, MD, DM, Department of Endocrinology, NMC Hospital, Dubai, United Arab Emirates (e-mail: sandeepch8j@gmail.com).
\end{abstract}
Abstract
Keywords
- Arab diabetes
- diabetes
- glycemic index
- glycemic load
- medical nutrition therapy

Date, the fruit of date palm, is a delicious fruit with a sweet taste and a fleshy mouth feel. Dates have been considered as the staple food in the Arab Gulf regions for thousands of years. The religious-cultural importance of this fruit often creates conflict between persons with diabetes, who wish to consume it in unlimited quantity, and health care professionals, who condemn its consumption. This article provides a balanced, nutrilogic opinion about dates and their consumption in diabetes.

\section{Introduction}

Phoenix dactylifera (date, date palm) is a flowering plant species of the palm family, Arecaceae. It has been cultivated since antiquity for its edible sweet fruit. ${ }^{1}$ The daily consumption of dates is deeply rooted in the tradition of many societies, including those in the United Arab of Emirates, and has religious sanction as well. It has been considered as a staple food of the Arab Gulf regions.

Date is a delicious fruit with a sweet, fleshy feeling. The development of the fruit is classified into four stages: "Kimiri," "Khalal," "Rutab," and "Tamer."

Dates are consumed in a variety of ways. They are mainly consumed as fresh (30-40\%) or in the dried form (60-70\%) at Rutab (semi-ripe) and Tamar (fully ripe) stages. Little or no processing is required.

\section{Dilemma in Diabetes}

Use of dates as a snack, as often as four to five times per day, is a part of Arabic culinary tradition. Date fruits are considered highly nutritious and healthy by the public. Persons with diabetes get confused as they receive conflicting messages from diabetes care providers. Whereas some encourage moderate consumption of dates, others advise restraint or abstinence from dates as a means to improve glycemic control.

\section{Nutritional Value}

Dates can be considered as an ideal food providing a wide range of essential nutrients with many potential health benefits. ${ }^{2}$ Dates are rich source of carbohydrates, salts, minerals, vitamins, fatty acids, and proteins. Dates are also a good source of dietary fiber, depending on the variety and stage of ripening $(6.4-11.5 \%)^{3}$

\section{Macronutrients}

Carbohydrates (sucrose, glucose, fructose), constitute around $70 \%$ of the energy of dates. These sugars are responsible for the sweet taste of dates. The carbohydrate content of dates depends on the type of date and the degree of ripeness with the highest concentration at the tamer stage. ${ }^{4}$

Dates contain almost half of the amount of sugars in the form of fructose. As fructose is twice as sweet as glucose, it plays an important role in the flavor and inducing a feeling of satiety. Dates have been shown to have low to medium glycemic index values, and therefore they may benefit glycemic and lipid control in diabetes. The low glycemic index of dates is due to the high fructose and dietary fiber content. ${ }^{5}$

Dates are a good source of dietary fiber. Dietary fiber content varies depending on the variety and degree of ripeness, and it ranges from 6.4 to $11.5 \%{ }^{6}$ Dietary fiber exhibits many therapeutic benefits. Higher content of the insoluble fiber 
induces satiety. It helps in lowering the blood cholesterol levels by preventing cholesterol absorption in the gut. High fiber is a bulk laxative. It protects the colonic mucosal membrane by decreasing exposure time to nutrients, as well as binding potential cancer-causing chemicals passing through the colon.

Protein and lipid are present in minor amounts in dates. Proteins are found in the date fruit in the range of 1 to $3 \%$. This percentage is higher than found in common fruits such as apples, papayas, oranges, bananas, pomegranates, and grapes. The date flesh and date seed both contain a wide variety of saturated and unsaturated fatty acids.

\section{Micronutrients}

Dates are a good source of many important vitamins and minerals. Dates contain high levels of selenium, copper, potassium, and magnesium. They also have moderate concentrations of manganese, iron, phosphorus, and calcium. The high-potassium and low-sodium content of dates help people with hypertension. ${ }^{7}$

Dates contain various types of phytochemicals such as carotenoids and phenolic compounds (flavonoids and anthocyanins), known as tannins that possess anti-infective, anti-inflammatory, and antihemorrhagic (prevent easy bleeding tendencies) properties. ${ }^{8}$

Dates have also been shown to reduce the oxidative stress by normalizing the increased hepatic levels of malondialdehyde (MDA) and by increasing the hepatic glutathione levels. ${ }^{9}$

Moderate amount of vitamin A found in dates is known to have antioxidant properties. It also facilitates healthy vision and helps maintain health of mucus membranes and skin.

The fruit has adequate levels of B-complex vitamins (pyridoxine [vitamin $\mathrm{B}_{6}$ ], niacin, pantothenic acid, riboflavin, and vitamin $\mathrm{K}$ ). These vitamins act as cofactors in multiple metabolic pathways that handle carbohydrates, protein, and fats. Vitamin $\mathrm{K}$ is essential for coagulation and bone health.

\section{Pragmatic Suggestions}

Dates can safely be consumed in small quantities. A single-pitted date weighing around $7.1 \mathrm{~g}$ provides 20 calories and should not upset glycemic homeostasis significantly.
Some suggestions for the safe use of drugs include the following:

- Spread the total quantity of dates to be consumed, throughout the day.

- Replace the seed with low calorie, low glycemic index foods such as cabbage, almonds, or walnuts.

- Eat and chew dates slowly.

- Cut dates into slivers to increase the fruit's surface area.

- Use small amounts of date paste in cooking.

Persons with diabetes must be counselled regarding the harms of excessive intake of dates. However, health care professionals should keep in mind the religious-cultural importance of consumption of dates. This will allow a balanced approach to the question of whether to consume dates or not. In general, a "glucologic" policy of moderation should be followed.

\section{Conflict of Interest}

None.

\section{References}

1 El Hadrami A, Al-Khayri JM. Socioeconomic and traditional importance of date palm. Emir J Food Agric 2012;24(5):371

2 Vayalil PK. Date fruits (Phoenix dactylifera Linn):an emerging medicinal food. Crit Rev Food Sci Nutr 2012;52(3):249-271

3 Ahmed IA, Ahmed AW, Robinson RK. Chemical composition of date varieties as influenced by the stage of ripening. Food Chem 1995;54(3):305-309

4 Al-Farsi MA, Lee CY. Nutritional and functional properties of dates: a review. Crit Rev Food Sci Nutr 2008;48(10):877-887

5 Ali A, Al-Kindi YS, Al-Said F. Chemical composition and glycemic index of three varieties of Omani dates. Int J Food Sci Nutr 2009;60(4, Suppl 4):51-62

6 Al-Shahib W, Marshall RJ. Dietary fibre content of dates from 13 varieties of date palm Phoenix dactylifera $\mathrm{L}$. Int J Food Sci Technol 2002;37(6):719-721

7 Al-Shahib W, Marshall RJ. The fruit of the date pal its possible use as the best food for the future? Int J Food Sci Nutr 2003;54(4):247-259

8 Biglari F, AlKarkhi AF, Easa AM. Antioxidant activity and phenolic content of various date palm (Phoenix dactylifera) fruits from Iran. Food Chem 2008;107(4):1636-1641

9 Bastway Ahmed M, Hasona NA, Selemain AH. Protective effects of extract from dates (Phoenix dactylifera L.) and ascorbic acid on thioacetamide-induced hepatotoxicity in rats. Iran J Pharm Res 2008;7(3):193-201 